\title{
Adult survival of Arctic terns in the Canadian High Arctic
}

\author{
Mark L. Mallory $\mathbb{1}^{\mathrm{a}, \mathrm{b}}$, Shanti E. Davis ${ }^{c}$, Mark Maftei ${ }^{c}$, Danielle T. Fife ${ }^{\mathrm{a}}$ \& Gregory J. Robertson ${ }^{\mathrm{d}}$
}

aBiology, Acadia University, Wolfville, NS, Canada; ${ }^{b}$ Canada Fulbright Chair in Arctic Studies, University of Washington, Seattle, WA, USA; 'High Arctic Gull Research Group, Bamfield, BC, Canada; dWildlife Research Division, Environment and Climate Change Canada, Mount Pearl, NL, Canada

\section{ABSTRACT}

Arctic tern (Sterna paradisaea) populations are thought to be in decline across much of their range. For long-lived seabirds, determining adult survival rates is key to understanding current population trends and predicting trajectories. We therefore examined adult survival of terns banded at our field site in the Canadian High Arctic between 2007 and 2016. Apparent adult survival was 0.883 , comparable to values for other tern species and for other Arctic larids. However, using this survival rate plus first year survival values from a recent study in Iceland, we project a declining trend for terns in the Canadian High Arctic, consistent with recent reports from local ecological knowledge and limited regional surveys. Our data suggest that low adult survival is not responsible for declining tern populations, and that studies should investigate whether dispersal to new nesting locations may be underway, or that young terns are not surviving well or recruiting to the population.

\section{KEYWORDS}

Sterna paradisaea; survival; larid; Arctic; banding

\section{ABBREVIATIONS}

AICc: Akaike Information Criterion, corrected for small sample size; $\mathrm{Cl}$ : confidence interval; CMR: capture-markrecapture; QAICc: Quasi-

likelihood of Akaike's

Information Criterion corrected for small sample size; SD: standard deviation

\section{Introduction}

Seabirds are considered one of the most threatened groups of birds on a global scale, with many species in decline (Croxall et al. 2012). Recent studies have suggested that declines in seabird populations are largely attributable to anthropogenic activities (Croxall et al. 2012), including interactions with fisheries (Regular et al. 2013), introductions of invasive species (Boersma et al. 2001) and pollution (Wiese et al. 2004; Wilcox et al. 2015). The effects of changing climate on seabird populations have also been evaluated, often with evidence of negative influences on reproduction and survival (Sandvik et al. 2005; Frederiksen et al. 2008; Irons et al. 2008; Descamps et al. 2017). Because most seabirds are relatively longlived and have low fecundity, an important factor influencing populations should be adult survival (Weimerskirch 2001). Therefore, determining adult survival rates and factors that influence survival is key to understanding current trends and predicting future seabird numbers (e.g., Saether \& Bakke 2000).

Despite the relative remoteness of Arctic regions, large-scale population declines have been reported for species like thick-billed murres (Uria lomvia; Frederiksen et al. 2016), black-legged kittiwakes (Rissa tridactyla; Descamps et al. 2017), glaucous gulls (Larus hyperboreus; Petersen et al. 2015), common eiders (Somateria mollissima; Gilliland et al. 2009) and ivory gulls (Pagophila eburnea; Gilchrist
\& Mallory 2005). Human harvest and interactions with fisheries have been implicated in some declines, and apparent adult survival of some Arctic species is influenced by climatic conditions (Sandvik et al. 2005; Hovinen et al. 2014). However, in many cases causes of declines remain unknown.

The Arctic tern (Sterna paradisaea) is a small seabird weighing about $110 \mathrm{~g}$, with a circumpolar breeding distribution, nesting primarily on low, flat, gravel or sand islands and peninsulas in the Arctic, although its breeding range extends south of the Arctic in both North America and Europe (Hatch 2002). This transequatorial migrant travels more than $90000 \mathrm{~km}$ annually from some breeding locations to their Antarctic wintering grounds and back (Egevang et al. 2010; Fijn et al. 2013). Recently, concern has been expressed regarding the circumpolar status of Arctic terns, with evidence from some locations suggesting that a broad decline in the population is underway, at least in the North Atlantic breeding population (Gilchrist \& Robertson 1999; Mitchell et al. 2004; Barrett et al. 2006; Maftei et al. 2015). Research on breeding terns has demonstrated years of deferred or failed breeding (Hatch 2002; Levermann \& Tottrup 2007) and dynamic regional movements of colonies, but overall no consistent, broad, long-term decline in reproductive effort or success has been detected (e.g., Egevang \& Frederiksen 2011; Vigfusdottir et al. 2013; Mallory et al. 2017). To date, no one has assessed whether low adult survival

CONTACT Mark L. Mallory mark.mallory@acadiau.ca B Biology Department, Acadia University, 33 Westwood Avenue, Wolfville, NS B4P 2R6, Canada 
in Arctic terns breeding at high latitudes could be contributing to declines.

To further our understanding of Arctic tern population dynamics, we estimated apparent adult survival and recapture probabilities of Arctic terns at a High-Arctic colony in Nunavut, Canada (Mallory et al. 2017). Extensive areas of Xanthoria elegans lichen growth (typical of sites with high nitrogen addition due to guano; Choy et al. 2010) suggested that terns have nested at the site since well before 2002, when the colony was first censused (Mallory \& Gilchrist 2003). Since 2007, the colony was studied annually to yield insights into tern diet (Pratte et al. 2017), contaminants (Akearok et al. 2010; Peck et al. 2016), biotransport of elements (Michelutti et al. 2010) and overall breeding biology (Mallory et al. 2017). As part of this research programme, adult terns were banded and recaptured in subsequent years to provide data for CMR analyses. Our objective was to generate the first estimate of adult survival for Arctic terns breeding at high latitudes, and to compare that to estimates with tern survival further south. We predicted that adult survival would be lower at our high latitude colony, given that local populations appeared in decline, but breeding parameters appeared typical of terns across their range (Mallory et al. 2017).

\section{Methods}

\section{Study site and captures}

We studied the breeding biology of Arctic terns at a colony (ca. 300 nests) on Nasaruvaalik Island in Penny Strait, Nunavut $\left(75^{\circ} 49^{\prime} \mathrm{N}, 96^{\circ} 18^{\prime} \mathrm{W}\right.$; Fig. 1), between early June and late August in 2007-2016 (annual duration of research was 1 week-3 months). Characteristics of the island and the colony are described by Maftei et al. (2015) and Mallory et al. (2017).

Starting in 2007, we trapped adult terns on their nest using a bownet during the first week of incubation (Salyer 1962). We weighed terns with a 300-g Pesola spring scale, took physical measurements (see Devlin et al. 2004; although we did not ascertain sex), attached a stainless steel, uniquely numbered band to the tarsus, and released the birds. Because of the challenges in seeing or reading bands on terns (i.e., short tarsi that are hidden under feathers when they are standing), it was not possible to collect resight information and all re-encounter information came from recaptures of adults in subsequent years, trapping adults on the nest.

\section{Statistical analyses}

To estimate apparent survival rates $(\varphi)$ and recapture rates $(p)$, standard CMR analyses (Pollock et al. 1990; Lebreton et al. 1992) were carried out in the programme MARK (White \& Burnham 1999). Only birds captured as adults were used in this analysis.
Encounter histories were created based on initial captures and subsequent recaptures of adult birds in following years. There were no encounters of birds in three years; in 2013 and 2014, terns arrived at the colony but did not attempt to breed, while in 2015, we undertook a very short field effort that precluded any capture efforts (but confirmed that terns were nesting). Consequently, the recapture parameter was fixed to 0 for the years 2013, 2014 and 2015.

We constructed a global model that included time variation in apparent survival and recapture rates $\left(\varphi_{t}, p_{t}\right)$, while the candidate model set included models with constant survival and recapture rates. Goodness-of-fit was assessed with the programme UCARE 2.3.4 (Choquet et al. 2009). If a transient effect (a reduction in apparent survival after first capture) was indicated by Test 3.SR (Pradel et al. 1997), models allowing newly marked individuals to have different survival than previously marked individuals were also considered in the candidate model set. In addition, the variance inflation factor $(\hat{c})$ was calculated based on the global model and the model including a transient effect (Choquet et al. 2009). AICc was used to choose the best-fitting model among candidate models and model weights were used to assess the relative fit of each model (Burnham \& Anderson 1998). If heterogeneity was indicated by the goodness-of-fit testing $(\hat{c}>1.0)$, model fit statistics were adjusted accordingly using QAICc (Cooch \& White 2014).

We constructed a simple Leslie-matrix type population projection model with two-age classes. The model was based on pre-breeding census, assumed breeding began in the second year of life (Hatch 2002), and that terns survived at adult rates after their first complete year of life. Fecundity was the product of hatching success, clutch size and survival of hatched young to the following year. Nest success (four years) and clutch size (five years) information was available for our study site (Mallory et al. 2017). However, fledging success and post-fledging juvenile survival were not; instead we used data from a long-term study (19742017) in Iceland that estimated survival from the posthatch period to their first year $(0.122 \pm 0.025$ SD based on Barker [1997] models using within-season recoveries of banded, dead Arctic tern chicks [A. Petersen, unpubl. data]). To assess the variation in population growth rates $(\lambda), 5000$ random projection matrices were constructed by taking random draws of the vital rates and $\lambda$ was extracted from each random matrix. For nest success and clutch size, the value for a random year was selected, while for juvenile and adult survival rates, random values were drawn from a beta distribution, based on the mean and SD of the estimate. Means are presented \pm SD. 


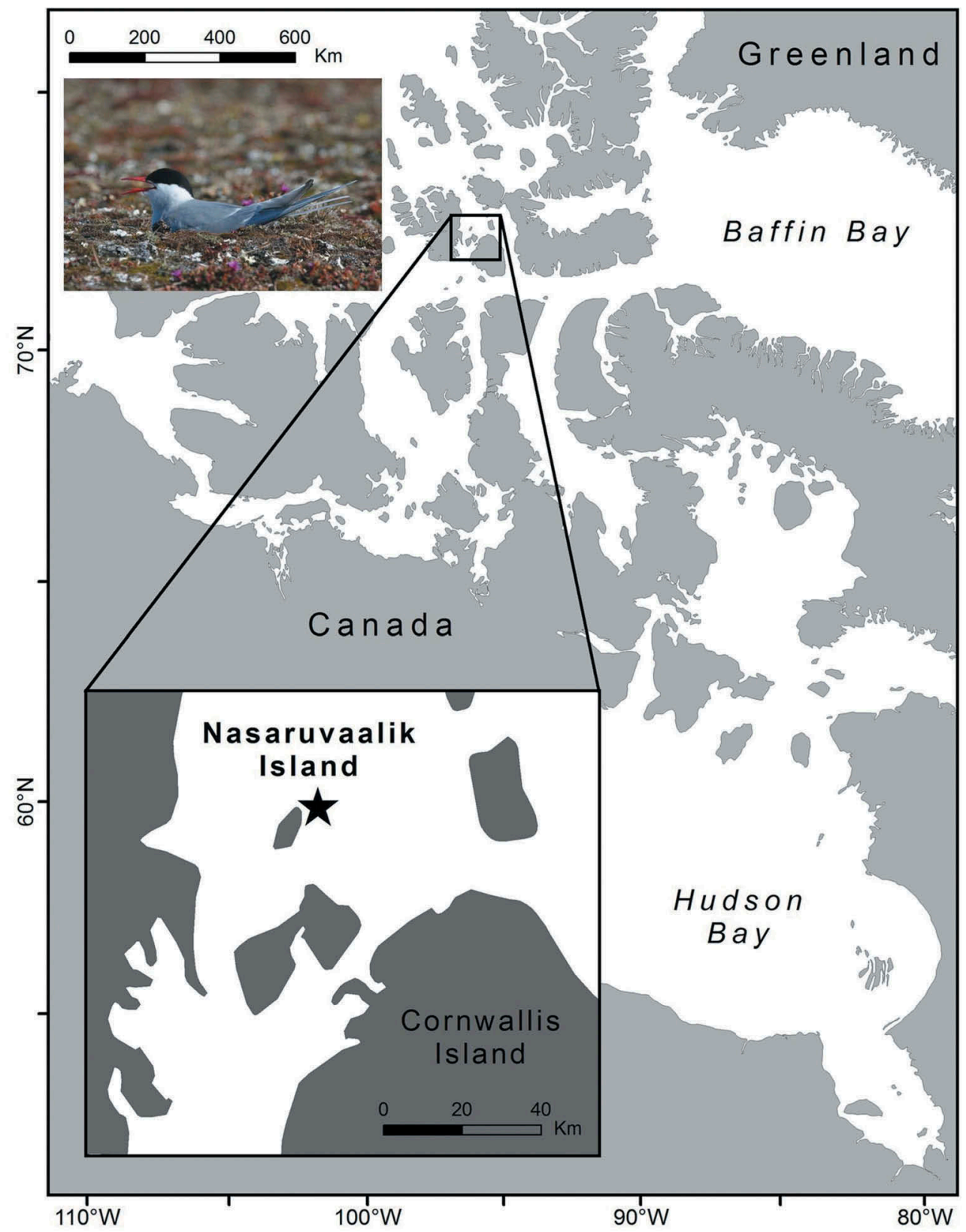

Figure 1. Location of the Nasaruvaalik Island study site in the Canadian High Arctic.

\section{Results}

We captured and banded 579 terns between 2007 and 2012. From these, 142 recaptures between 2008 and 2012 and 2016 were available for analysis (Table 1). Banding effort was uneven across years (Table 1). There were no apparent injuries or mortalities resulting from these capture efforts.

\section{Goodness of fit}

Tests from Programme UCARE indicated sources of heterogeneity. Test 3.SR was significant, indicating that newly banded terns had different survival rates than terns that were previously banded (Table 2). Additionally, Test 2.CL, a test that has no clear biological interpretation, was significant (Table 2). To address these sources of heterogeneity, models that
Table 1. Summary of annual banding and recaptures of breeding Arctic terns at Nasaruvaalik Island, Nunavut, Canada, 2007-2016. New bandings in 2016 are not reported because they occurred in the final occasion of the study and did not inform estimates of apparent survival $(\varphi)$ and recapture $(p)$.

\begin{tabular}{cccc}
\hline Year & $\begin{array}{c}\text { Number of } \\
\text { newly banded } \\
\text { terns }\end{array}$ & $\begin{array}{c}\text { Number of } \\
\text { terns } \\
\text { recaptured }\end{array}$ & $\begin{array}{c}\text { Number of terns } \\
\text { subsequently recaptured in } \\
\text { future years }\end{array}$ \\
\hline 2007 & 59 & & 22 \\
2008 & 29 & 6 & 7 \\
2009 & 49 & 1 & 23 \\
2010 & 186 & 12 & 38 \\
2011 & 87 & 25 & 24 \\
2012 & 169 & 59 & 28 \\
2016 & & 39 & \\
\hline
\end{tabular}

allowed for survival to differ between newly and previously marked individuals were included in the model set, and $\hat{c}$ was adjusted to 1.94 to address the general heterogeneity indicted by Test 2.CL (Table 2). 
Table 2. Summary of goodness-of-fit testing for encounters of banded breeding Arctic terns at Nasaruvaalik Island, Nunavut, Canada, 2007-2016. Test results are from UCARE 2.3.4 (Choquet et al. 2009). The overall test for the global model (Cormack-JollySeber, or annual variation in apparent survival $\varphi_{t}$ and recapture $p_{t}$ ) is the sum of all four tests, while the test allowing for apparent survival to differ for individuals newly marked $\left(\varphi_{t / t}\right)$, is the sum of all tests excluding Test 3.SR. $\hat{c}$ is calculated as $\chi^{2} / \mathrm{df}$.

\begin{tabular}{lrccc}
\hline Test & $\chi^{2}$ & $\mathrm{df}$ & $p$ value & $\hat{c}$ \\
\hline $3 . \mathrm{SR}$ & 11.31 & 5 & 0.046 & \\
$3 . \mathrm{SM}$ & 5.74 & 3 & 0.124 & \\
$2 . \mathrm{CT}$ & 4.01 & 4 & 0.406 & \\
$2 . \mathrm{CL}$ & 9.68 & 3 & 0.022 & \\
Global model $\left(\varphi_{t} p_{t}\right)$ & 30.75 & 15 & 0.009 & 2.05 \\
Model $\left(\varphi_{t / t} p_{t}\right)$ & 19.43 & 10 & 0.011 & 1.94 \\
\hline
\end{tabular}

\section{Survival models}

The model which received the most support allowed for differences in apparent survival between new and previously marked terns, with annual variation for newly marked terns and a constant apparent survival for previously marked terns (Table 3). Models allowing for annual variation in recapture were supported across the entire model set (Table 3). From the best fitting model $\left(\varphi_{t /} p_{t}\right)$, for newly marked terns, annual apparent survival ranged from 0.265 to 0.927 , and each annual estimate had wide confidence intervals. Apparent survival for previously marked terns was estimated at $0.883 \pm 0.126$ (95\% CI: 0.406-0.988), while recapture ranged from 0.020 to 0.360 across the years of study. To understand the effect of including data from 2016, four years after the penultimate capture occasion in 2012, we constructed similar models excluding this occasion. When excluding 2016, models failed to converge and provided meaningless estimates, indicating the data from 2016 was essential to allow for an estimate of apparent survival.

Table 3. Model selection results for Arctic terns breeding at Nasaruvaalik Island, Nunavut, Canada, 2007-2016. The survival rate $(\varphi)$ and the recapture rate $(p)$ subscripted with time $(t)$ indicate that the rates were allowed to vary annually, while $(t / t$ or ./.) indicates that survival rates were estimated separately for the year after first capture compared to survival in future. In all models, recaptures rates for 2013 to 2015 were fixed to 0 . Model fitting results were adjusted for overdispersion $(\hat{c}=1.94)$. QDeviance is an index of model fit, while QAICc is a measure of the model's ability to explain the data. $\triangle \mathrm{QAICC}$ is simply the QAICc difference between the best (lowest AICc) model and the model in question, while the QAICc weight is the relative support of each model compared to all others in the model set.

\begin{tabular}{lccccc}
\hline Model & $\begin{array}{c}\text { Number of } \\
\text { parameters }\end{array}$ & QDeviance & QAICc & $\Delta$ QAICc & $\begin{array}{c}\text { QAICc } \\
\text { weight }\end{array}$ \\
\hline$\varphi_{t / .} p_{t}$ & 13 & 29.58 & 485.66 & 0.00 & 0.652 \\
$\varphi_{\text {./. }} p_{t}$ & 8 & 43.15 & 488.90 & 3.24 & 0.129 \\
$\varphi_{t} p_{t}$ & 7 & 46.56 & 490.27 & 4.60 & 0.065 \\
$\varphi_{t} p_{t}$ & 11 & 39.41 & 491.34 & 5.68 & 0.038 \\
$\varphi_{t / t} p_{t}$ & 16 & 29.41 & 491.77 & 6.11 & 0.031 \\
$\varphi_{. / t} p_{t}$ & 12 & 37.83 & 491.84 & 6.18 & 0.030 \\
$\varphi_{t / .} p$ & 8 & 47.00 & 492.76 & 7.09 & 0.019 \\
$\varphi_{\text {./. } p}$ & 3 & 57.20 & 492.78 & 7.11 & 0.018 \\
$\varphi p$ & 2 & 59.96 & 493.52 & 7.86 & 0.013 \\
$\varphi_{t / t} p$ & 12 & 41.90 & 495.91 & 10.25 & 0.004 \\
$\varphi_{t} p$ & 7 & 55.42 & 499.13 & 13.46 & 0.001 \\
\hline
\end{tabular}

Our simple population projection suggested a declining population (mean $\lambda: 0.954 \pm 0.127$, median: 0.991 ), but $95 \%$ confidence intervals were very wide (0.601-1.099).

\section{Discussion}

Among the Charadriiformes, adult annual survival is generally high, typically $>0.85$, and specifically in tern species, annual adult survival has been reported as $75-93 \%$ (summarized by Schreiber \& Burger 2001, calculated by a variety of methods). Using modern CMR approaches, survival rate estimates are more robust and are generally higher than estimated by earlier methods (ca. 90\%, although annual survival estimates can vary considerably [Ledwoń et al. 2013; Liechty et al. 2017]). In the case of Arctic terns, early reports of annual survival (based on resighting) in the UK were 0.82-0.875 (Cullen 1957; Coulson \& Horobin 1976; Cramp 1983). More recently, Devlin et al. (2008), working on Arctic terns at the southern limit of their range in North America, used CMR analyses and found apparent adult survival varied among nesting islands, and averaged 0.80 at Machias Seal Island (where terns had abandoned breeding [Gaston, Bertram et al. 2009]), but was $>0.89$ at three other sites. Consequently, our results suggesting apparent adult survival of 0.883 places Arctic terns in the Canadian High Arctic at similar survival to terns breeding further south in North America, including other Sterna species (Payo-Payo et al. 2018) and a little lower than recent rates of other tern species (Ledwoń et al. 2013). Moreover, adult tern survival was in the range of estimates for other Arctic larids breeding in Nunavut: glaucous gulls-0.84-0.86 (Gaston, Descamps et al. 2009; Allard et al. 2010); Thayer's gulls (Larus thayeri) 0.81 (Allard et al. 2010) and Sabine's gulls (Xema sabini) -0.90 (Fife et al. 2018).

There was some evidence of a transient effect in our data, which is not uncommon (Sandercock 2006), and was found for Arctic terns studied in the Bay of Fundy (Devlin et al. 2008). We also detected other sources of heterogeneity, but mild heterogeneity has been seen in other survival studies of terns (Liechty et al. 2017), so is not unexpected. We note that between 2002 and 2012, the breeding population of Arctic terns at this colony and in this region appeared to be in decline (Maftei et al. 2015). Our simplistic projection model also suggested a decline $(4.6 \% /$ year), acknowledging that there was large uncertainty in the projections (largely due to the wide confidence intervals in our estimates of adult survival), and that juvenile survival rates were extracted from a study in Iceland. We assumed that terns began breeding in their second year, but if most do not start until their third year, the model projects slightly steeper 
declines (mean $\lambda: 0.946 \pm 0.133$, median: $0.989,95 \%$ CI 0.593-1.091; meaning a 5.4\%/year decline).

We initially tried to undertake a CMR analysis with data from 2007 to 2012, which normally should allow researchers to generate a survival estimate (assuming sample sizes and/or resighting rates are sufficient [e.g., Stenhouse \& Robertson 2005; Allard et al. 2010]). However, we were not able to meaningfully estimate survival and recapture parameters based on the data from that five-year period, probably due to low numbers of recaptures years in some years. We then experienced two consecutive years of no breeding attempts at the field site, followed by a year when we were unable to recapture birds. Consequently, there was a four-year gap between penultimate and ultimate banding efforts, but the 2016 tern recaptures were essential to generate credible values for an average estimate of survival. Although annual variation in survival was not indicated by model selection (at least for previously marked terns, which is assumed to better reflect survival as opposed to emigration), this does not indicate the survival did not vary across years. Most likely we were unable to detect any annual variation, especially with the heterogeneity present in the data. Sandvik et al. (2005) and Frederiksen et al. (2008) showed that change underway in climatic conditions, or extreme weather events, have a deleterious effect on adult survival in other seabirds breeding in the North Atlantic. Long-distance migrants are expected to be even more vulnerable to climate variation (Both et al. 2009), and evidence from sympatrically-nesting Sabine's gulls, another trans-equatorial migrant breeding at this site, found that annual survival was lower during anomalous climatic conditions in the wintering grounds or migration sites (Fife et al. 2018). Interestingly, Sabine's gulls also deferred nesting in the two years that Arctic terns did; whether this was a response by both species to local climatic conditions (and resulting effects on foraging or nesting) or a response to conditions on the wintering or migration grounds is unknown.

Despite their ubiquitous presence around the circumpolar Arctic, most of what we know about Arctic terns comes from studies in the middle or southern parts of their range (Hatch 2002), and little is known about Arctic tern adult survival, or the factors influencing their decisions to breed or to move colony locations (Hatch 2002; Levermann \& Tottrup 2007; Mallory et al. 2017). Collectively, Arctic seabird scientists and indigenous northern residents are expressing concern over apparent declines in numbers of terns (see Mallory et al. 2017), but our data do not support the hypothesis that low adult survival is responsible for declining Arctic tern populations. Given that recent studies do not suggest a broad decline in reproductive effort or success (Egevang \&
Frederiksen 2011; Vigfusdottir et al. 2013; Mallory et al. 2017), we strongly recommend that researchers assess whether reduced juvenile survival/recruitment, and/or adult dispersal and colony re-distribution, which is common in terns (Hatch 2002), may explain apparent declines.

\section{Acknowledgements}

We thank the many field assistants for their diligent work to capture and band terns at Nasaruvaalik Island, and Aevar Petersen for providing unpublished data on young tern survival. All annual expeditions were conducted under approved animal care and scientific permits, including ECPNR-11-020, NUN-SCI-09-01 and WL 2010-042. Finally, we thank Morten Frederiksen and Ana Sanz Aguilar for their insightful and helpful comments on our manuscript.

\section{Disclosure statement}

No potential conflict of interest was reported by the authors.

\section{Funding}

Support was provided by Environment and Climate Change Canada, Natural Sciences and Engineering Research Council Canada, Natural Resources Canada, Acadia University, and Fulbright Canada.

\section{ORCID}

Mark L. Mallory (D) http://orcid.org/0000-0003-2744-3437

\section{References}

Akearok J., Hebert C., Braune B.M. \& Mallory M.L. 2010. Inter- and intraclutch variation in egg mercury levels in marine bird species from the Canadian Arctic. Science of the Total Environment 408, 836-840.

Allard K.A., Gilchrist H.G., Breton A.R., Gilbert C.D. \& Mallory M.L. 2010. Apparent survival of adult Thayer's and glaucous gulls nesting sympatrically in the Canadian Arctic. Ardea 98, 43-50.

Barker R.J. 1997. Joint modelling of live-recapture, tagresight, and tag-recovery data. Biometrics 53, 666-677.

Barrett R.T., Lorentsen S.-H. \& Anker-Nilssen T. 2006. The status of breeding seabirds in mainland Norway. Atlantic Seabirds 8, 97-126.

Boersma P.D., Clark J.A. \& Hillgarth N. 2001. Seabird conservation. In E.A. Schreiber \& J. Burger (Eds.), Biology of marine birds (pp. 559-579). Boca Raton, FL: CRC Press.

Both C., Van Turnhout C.A., Bijlsma R.G., Siepel H., Van Strien A.J. \& Foppen R.P. 2009. Avian population consequences of climate change are most severe for longdistance migrants in seasonal habitats. Proceedings of the Royal Society B 277, 1259-1266.

Burnham K.P. \& Anderson D.R. 1998. Model selection and inference: a practical information-theoretic approach. New York: Springer.

Choquet R., Lebreton J.D., Gimenez O., Reboulet A.M. \& Pradel R. 2009. U-CARE: utilities for performing 
goodness of fit tests and manipulating capture-recapture data. Ecography 32, 1071-1074.

Choy E.S., Kimpe L.E., Mallory M.L., Smol J.P. \& Blais J.M. 2010. Contamination of an Arctic terrestrial food web with marine-derived persistent organic pollutants transported by breeding seabirds. Environmental Pollution 158, 3431-3438.

Cooch E.G. \& White G.C. 2014. Program MARK: a gentle introduction. 13th ed. Fort Colins, CO: Colorado State University.

Coulson J.C. \& Horobin J. 1976. The influence of age on the breeding biology and survival of the Arctic tern Sterna paradisaea. Journal of Zoology (London) 178, 247-260.

Cramp S. 1983. The birds of the western Palearctic. Vol. 3. Oxford: Oxford University Press.

Croxall J.P., Butchart S.H., Lascelles B.E.N., Stattersfield A. J., Sullivan B., Symes A. \& Taylor P. 2012. Seabird conservation status, threats and priority actions: a global assessment. Bird Conservation International 22, 1-34.

Cullen J.M. 1957. Plumage, age and mortality in the Arctic tern. Bird Study 4, 197-207.

Descamps S., Anker-Nilssen T., Barrett R., Irons D., Merkel F., Robertson G., Yoccoz N., Mallory M., Montevecchi W., Boertmann D., Artukhin Y., Christensen-Dalsgaard S., Erikstad K.-E., Gilchrist G., Labensen A., Lorentsen S.-H., Mosbech A., Olsen B., Petersen A., Rail J.-F., Renner H., Strøm H., Systad G., Wilhelm S. \& Zelenskaya L. 2017. Circumpolar dynamics of a marine top-predator track ocean warming rates. Global Change Biology 23, 3770-3780.

Devlin C.M., Diamond A.W., Kress S.W., Hall C.S. \& Welch L. 2008. Breeding dispersal and survival of Arctic terns (Sterna paradisaea) nesting in the Gulf of Maine. Auk 125, 850-858.

Devlin C.M., Diamond A.W. \& Saunders G.W. 2004. Sexing Arctic terns in the field and laboratory. Waterbirds 27, 314-320.

Egevang C. \& Frederiksen M. 2011. Fluctuating breeding of Arctic terns (Sterna paradisaea) in Arctic and HighArctic colonies in Greenland. Waterbirds 34, 107-111.

Egevang C., Stenhouse I.J., Phillips R.A., Petersen A., Fox J. W. \& Silk J.R.D. 2010. Tracking of Arctic terns Sterna paradisaea reveals longest animal migration. Proceedings of the National Academy of Sciences 107, 2078-2081.

Fife D.T., Davis S.E., Robertson G.J., Gilchrist H.G., Stenhouse I.J., Shutler D. \& Mallory M.L. 2018. Correlating tropical climate with survival of an Arcticbreeding, trans-equatorial migrant seabird. Arctic Science, doi: 10.1139/as-2017-0018.

Fijn R.C., Hiemstra D., Phillips R.A. \& van der Winden J. 2013. Arctic terns Sterna paradisaea from the Netherlands migrate record distances across three oceans to Wilkes Land, East Antarctic. Ardea 101, 3-12.

Frederiksen M., Daunt F., Harris M.P. \& Wanless S. 2008. The demographic impact of extreme events: stochastic weather drives survival and population dynamics in a long-lived seabird. Journal of Animal Ecology 77, 1020-1029.

Frederiksen M., Descamps S., Erikstad K.E., Gaston A.J., Gilchrist H.G., Johansen K.L., Kolbeinsson Y., Linnebjerg J.F., Mallory M.L., McFarlane Tranquilla L. A., Merkel F.R., Montevecchi W.A., Mosbech A., Reiertsen T.K., Robertson G.J., Strøm H. \& Thórarinsson T.L. 2016. Migratory connectivity of a declining seabird on an ocean basin scale: conservation implications. Biological Conservation 200, 26-35.
Gaston A.J., Bertram D.F., Boyne A.W., Chardine J.W., Davoren G., Diamond A.W., Hedd A., Montevecchi W. A., Hipfner J.M., Lemon M.J., Mallory M.L., Rail J.F. \& Robertson G.J. 2009. Changes in Canadian seabird populations and ecology since 1970 in relation to changes in oceanography and food webs. Environmental Reviews 17, 267-286.

Gaston A.J., Descamps S. \& Gilchrist H.G. 2009. Reproduction and survival of glaucous gulls breeding in an Arctic seabird colony. Journal of Field Ornithology 80, 135-145.

Gilchrist H.G. \& Mallory M.L. 2005. Declines in abundance and distribution of the ivory gull (Pagophila eburnea) in Arctic Canada. Biological Conservation 121, 303-309.

Gilchrist H.G. \& Robertson G.J. 1999. Population trends of gulls and Arctic terns nesting in the Belcher Islands, Nunavut. Arctic 52, 325-331.

Gilliland S.G., Gilchrist H.G., Rockwell R.F., Robertson G. J., Savard J.P.L., Merkel F. \& Mosbech A. 2009. Evaluating the sustainability of harvest among northern common eiders Somateria mollissima borealis in Greenland and Canada. Wildlife Biology 15, 24-36.

Hatch J.J. 2002. Arctic tern (Sterna paradisaea). In A. Poole (ed.): The birds of North America. Cornell Lab of Ornithology, Ithaca, NY. Accessed on the internet at http://bna.birds.cornell.edu/bna/species/707 in February 2016.

Hovinen J.E., Welcker J., Descamps S., Strøm H., Jerstad K., Berge J. \& Steen H. 2014. Climate warming decreases the survival of the little auk (Alle alle), a High Arctic avian predator. Ecology \& Evolution 4, 3127-3138.

Irons D.B., Anker-Nilssen T., Gaston A.J., Byrd G.V., Falk K., Gilchrist G., Hario M., Hjernquist M., Krasnov Y.V., Mosbech A. \& Olsen B. 2008. Fluctuations in circumpolar seabird populations linked to climate oscillations. Global Change Biology 14, 1455-1463.

Lebreton J.-D., Burnham K.P., Clobert J. \& Anderson D.R. 1992. Modeling survival and testing biological hypotheses using marked animals: a unified approach with case studies. Ecological Monographs 62, 67-118.

Ledwoń M., Neubauer G. \& Betleja J. 2013. Adult and prebreeding survival estimates of the whiskered tern Chlidonias hybrida breeding in southern Poland. Journal of Ornithology 154, 633-643.

Levermann N. \& Tottrup A.P. 2007. Predator effect and behavioural patterns in Arctic terns (Sterna paradisaea) and Sabine's gulls (Xema sabini) during a failed breeding year. Waterbirds 30, 417-420.

Liechty J.S., Minor A.K., Nepshinsky M. \& Pierce A.R. 2017. Apparent survival of royal tern Thalasseus maximus and Sandwich tern T. sandvicensis at Isles Dernieres Barrier Islands Refuge, Louisiana, USA. Marine Ornithology 45, 83-88.

Maftei M., Davis S.D. \& Mallory M.L. 2015. Assessing regional populations of ground-nesting marine birds in the Canadian High Arctic. Polar Research 34, article no. 25505, doi: 10.3402/polar.v34.25055.

Mallory M.L., Boadway K.A., Davis S.D., Maftei M. \& Diamond A.W. 2017. Breeding biology of Arctic terns (Sterna paradisaea) in the Canadian High Arctic. Polar Biology 40, 1515-1525.

Mallory M.L. \& Gilchrist H.G. 2003. Marine birds breeding in Penny Strait and Queens Channel, Nunavut, Canada. Polar Research 22, 399-403. 
Michelutti N., Blais J.M., Mallory M.L., Brash J., Thienpont J., Kimpe L.E., Douglas M.S.V. \& Smol J.P. 2010. Trophic position influences the efficacy of seabirds as metal biovectors. Proceedings of the National Academy of Sciences 107, 10543-10548.

Mitchell P.I., Newton S.F., Ratcliffe N. \& Dunn T.E. 2004. Seabird populations of Britain and Ireland: results of the Seabird 2000 census (1998-2002). London: T \& AD Poyser.

Payo-Payo A., Sanz-Aguilar A., Gaglio D., Sherley R., Cook T., Altwegg R. \& Ryan P. 2018. Survival estimates for the greater crested tern Thalasseus bergii in southern Africa. African Journal of Marine Science 40, 43-50.

Peck L.E., Gilchrist H.G., Mallory C.D., Braune B.M. \& Mallory M.L. 2016. Persistent organic pollutant and mercury concentrations in eggs of marine birds breeding in the Canadian High Arctic. Science of the Total Environment 556, 80-88.

Petersen A., Irons D., Gilchrist H.G., Robertson G.J., Boertmann D., Strom H., Gavrilo M., Artukhin Y., Kuletz K. \& Mallory M.L. 2015. The status of glaucous gulls Larus hyperboreus in the circumpolar Arctic. Arctic 68, 107-120.

Pollock K.H., Nichols J.D., Brownie C. \& Hines J.E. 1990. Statistical inference for capture-recapture experiments. Wildlife Monographs 107. Bethesda, MD: The Wildlife Society.

Pradel R., Hines J.E., Lebreton J.-D. \& Nichols J.D. 1997. Capture-recapture survival models taking account of transients. Biometrics 53, 60-72.

Pratte I., Boadway K.A., Davis S.E., Maftei M. \& Mallory M.L. 2017. Diet dichotomy between two migrant seabirds breeding near a High Arctic polynya. Royal Society Open Science 4, article no. 160982, doi: 10.1098/ rsos.160982.

Regular P.M., Montevecchi W.A., Hedd A., Robertson G. \& Wilhelm S. 2013. Canadian fishery closures provide a large-scale test of the impact of gillnet bycatch on seabird populations. Biology Letters 9, article no. UNSP 20130088, doi: 10.1098/rsbl.2013.0088.

Saether B.E. \& Bakke O. 2000. Avian life history variation and contribution of demographic traits to the population growth rate. Ecology 81, 642-653.

Salyer J.W. 1962. A bow-net trap for ducks. Journal of Wildlife Management 26, 219-221.

Sandercock B.K. 2006. Estimation of demographic parameters from live-encounter data: a summary review. Journal of Wildlife Management 70, 1504-1520.

Sandvik H., Erikstad K.E., Barrett R.T. \& Yoccoz N.G. 2005. The effect of climate on adult survival in five different species of North Atlantic seabirds. Journal of Animal Ecology 74, 817-831.

Schreiber E.A. \& Burger J. 2001. Biology of marine birds. New York: CRC Press.

Stenhouse I.J. \& Robertson G.J. 2005. Philopatry, site tenacity, mate fidelity, and adult survival in Sabine's gulls. Condor 107, 416-423.

Vigfusdottir F., Gunnarsson T.G. \& Gill J.A. 2013. Annual and between-colony variation in productivity of Arctic Terns in west Iceland. Bird Study 60, 289-297.

Weimerskirch H. 2001. Seabird demography and its relationship with the marine environment. In E.A. Schreiber \& J. Burger (eds.): Biology of marine birds. Pp. 115-136. Boca Raton, FL: CRC Press.

White G.C. \& Burnham K.P. 1999. Program Mark: survival estimation from populations of marked animals. Bird Study (Supplement) 46, S120-S139.

Wiese F.K., Robertson G.J. \& Gaston A.J. 2004. Impacts of chronic marine oil pollution and the murre hunt in Newfoundland on thick-billed murre Uria lomvia populations in the eastern Canadian Arctic. Biological Conservation 116, 205-216.

Wilcox C., Van Sebille E. \& Hardesty B.D. 2015. Threat of plastic pollution to seabirds is global, pervasive, and increasing. Proceedings of the National Academy of Sciences 112, 11899-11904. 